\title{
Research on Straw and Willow Plaiting in Shandong and Traditional Craft
}

\author{
Xia Fenghua, Pan Wei, Bian Xiaowen, Cui Miaomiao, Gao Liyan
}

Binzhou Polytechnic, Binzhou, China

Email:18654356826@126.com

Keywords: straw and willow plaiting; folk custom; traditional craft

\begin{abstract}
Straw and willow plaiting is a kind of traditional handicraft technique to plait handicraft works or household items with natural materials, such as straw, wheat-straw, corn bran, willow twig, rattan, palm and etc. as raw materials. The combination of technological process of straw and willow plaiting, humanized design and modern indoor design is more conductive to the development of straw and willow plaiting industry and indoor design arts. This paper discusses the relationship between straw and willow plaiting and traditional handicraft. Straw and willow plaiting, with a long history, originates from Shandong Province and develops gradually across the country. Traditional straw and willow plaiting is mainly for practical application, supplemented by the function of aesthetic appreciation, whereas, modern straw and willow plaiting continuously integrates traditional techniques and modern life and creates the application of willow plaiting products. According to process materials, straw and willow plaiting mainly includes straw plaiting, palm plaiting, rattan plaiting, willow twig plaiting, corn bran plaiting, bamboo plaiting and etc. It can also be divided into flat plaiting, twisting plaiting, tightening plaiting and so on based on techniques. As a kind of traditional technique, straw and willow plaiting is full with national character and techniques, and its products essentially manifest unique artistic concept and aesthetic orientation of Chinese nation, which is also the artistic expression and sublimation of production and life, folk custom and national culture in each nation. Willow plaiting material is sustainable material with rich cultural connotation.
\end{abstract}

\section{History of Straw and Willow Plaiting}

Straw and willow plaiting is handicraft works or household items plaited with thatch, wheat-straw, corn bran, willow twigs and etc. According to textual research of some scholars, handle products with twisting pattern of red pottery appeared early in Longshan cultural period, and then willow plaited objects follow this widely used pattern. In other words, it was relatively common that people used willow plaited objects in downstream of the Yellow River four or five thousand years ago. Some scholars believe that straw and willow plaiting originates from Shandong area 1500 years ago. It was called "Straw Plait of Ye County" in Ming Dynasty, so straw plait of Ye County is also called "Laizhou Straw Plait". Straw and willow plaiting products were widely used during the reign of Emperor Jiaqing of the Qing Dynasty. From the history of straw and willow plaiting, in self-sufficient lifestyle of traditional agricultural society, people used local willow twigs to plait large wicker basket, dustpan, plaited basket, food container, bamboo fish trap and so on for agriculture and fishery production, straw and willow plaiting was widely used by people in daily life, mainly self-made for self-use. It is also mainly for practical application, supplemented by the function of aesthetic appreciation.

In modern society, straw and willow plaiting has gradually become an industry in large-scale production and operation. With its rich artistic, local and personalized characteristics, straw and willow plaiting even enters commodity circulation in international trade. At the same time, the production of straw and willow plaiting incessantly expands and innovates the application methods of straw and willow plaiting products by integrating traditional techniques and modern life for indoor design.

Raw materials for straw and willow plaiting in China are various and diversified all over the 
whole country, and the major place of production now is Huang-Huai-Hai region. Straw and willow plaiting products in different places are with different characteristics according to local conditions. For instance, bamboo plaiting is more in Anhui and Zhejiang Province; wheat-straw plaiting is more common in North China, like Shandong and Henan Province; rattan plaiting is more advanced in southern provinces and cities like Guangdong and Yunnan Province. From the perspective of raw material, therophyte herbaceous plant or woody plant are more used as raw material for straw and willow plaiting, including thatch, straw, rattan, palm and etc., with short growth cycle, high product rate, low cost and easy access. Besides, from the perspective of techniques, straw and willow plaiting comes from folk production with various plaiting textures, simple and easy to learn. Therefore, it develops popularly across the country, and it is common that straw and willow plaiting products are in wide application.

\section{Classification of Straw and Willow Plaiting}

\subsection{Classification by craft material}

Straw and willow plaiting is a kind of diversified Chinese traditional crafts. From material and production, Chinese traditional crafts generally include sculpturing craft, smithing craft, firing craft, woodcraft, weaving and dyeing craft, and carving craft. Straw and willow plaiting belongs to plaiting and weaving craft, because traditional plaited products were containers of daily life and production, such as dustpan, large wicker basket, wicker bag, vegetable basket, sewing basket and etc. In modern society, plaited products are also widely applied in production and life, including laundry basket, flowerpot, accessories, animal cage, fruit plate and so on.

Straw plaiting is handmade plaiting with various kinds of straw and wheat-straw. Straw plaiting in Shandong Province is most well-known with unique straw plait.

Palm plaiting has a long history, and its raw material is palm leaves. As legend records, straw rain cape is invented by Yu Yao to seek shelter from wind and rain and fierce beast. At that time, Yu Yao has nothing to wear, so he plaited straw rain cape with palm to wear when ascending the throne and accept respects of common people, so straw rain cape was popular as holy garment. The selection of raw material for palm plaiting is strict, and the seasonality of palm production is strong. The process technology of palm plaiting is divided into several steps. First of all, palm leaves are selected, scribed and cut into thin thread with needle, and rubbed to rope, then, after fumigation, soaking and drying, the palm rope plaited will be pure white and soft. Finally, living products or crafts like hat or mat will be plaited in the form of herringbone, or supplemented by wood or paper to decorate the pattern. Plain colored palm plaited finished products are elegant like silk, whereas, colored palm plaiting after dyeing is more suitable for home decoration, mainly with exquisite jacquard and applique pattern.

In addition, craft products of palm plaiting mainly consist of shoes, hat, bag, fruit plate, toy, fan, chair and so on, with various patterns and colors. Slipper plaited by hemp rope are two-layer and three-layer in thickness, solid and wear-resisting, lightweight and breathable, with various common patterns like birds and flowers and coordinated natural color. Plaited hat is mainly herringbone, flexible and elastic. Plaited toys, in general, select palm in white or primary color to make animal images, such as rabbit, dog, pig, horse and etc. with lively buckle plaiting, knotting, and twisting plaiting techniques. However, some animal toys plaited with colored palm are colorful not vulgar with strong color contrast. What's more, raw material for modern palm plaiting is finer and more lightweight than traditional palm plaiting.

The raw material of rattan plaiting is the stem of vine plants. From the Western Zhou Dynasty to the Warring States Period, rattan basket was the folk production tool for loading in south area. At that time, people began to consider not only the practical application when making rattan products, but also aesthetic appreciation. The biggest characteristic and advantage of rattan is strong toughness, flexible, solid and durable, but not easy to fracture.

Willow twig and bamboo plaiting mainly use willow twig and bamboo cane as raw material respectively. The major production place of willow plaiting is Shandong and Jiangsu Province, 
whereas, the bamboo plaiting is mainly in Sichuan Province.

\subsection{Classification by production process}

Willow plaiting is to form fixed form by slip stitch, pressing, cross plaiting forward and backward with longitude and latitude willow or willow twig and hemp rope. From plaiting form, it can be divided into horizontal plaiting, lace plaiting, vertical plaiting and stich plaiting. From plaiting method, it include flat plaiting, twisting plaiting and tightening plaiting.

Flat plaiting is to cross and form different patterns and various geometric pattern according to crossing relation of longitude and latitude willow. It is necessary to perform underpainting first, including such types as circular type, elliptic type, and rectangle and such patterns as sunflower pile, piles of Chinese character "mi" and "feng" and so on. Flat plaiting is also can be applied to the combination of willow, wood veneer and rush straw, or willow twigs are peeled into flat sheets to create new patterns.

Twisting plaiting, also called "screwing plaiting", is mainly to make appliance in circular type, like vase. Its advantage is solid structure and unique patterns. Materials for twisting plaiting are required to be soft and elastic, and the surface will be covered by weft knitting. The pile is shall be plaited first, then twigs cross the pile upward and downward.

Tightening plaiting, also called "whipping plaiting”, is to form rhombus pattern by pressing and tightening. It is compact, solid and durable. The tools for tightening plaiting include snip, awl, grooving awl, crochet hook, bamboo split knife, measuring scale and so on. Snip is used to sharpen willow twig to ensure moderate thickness; flat grooving awl is used to twine; square taper is to drill in dustpan tongue; crochet hook is to hook rope in dustpan tongue, also called "tuoluozi"; cord weight is to twine rope to save labor and ensure the appropriate tightness, and the modelling of circular type.

\subsection{Classification by plaiting category}

Based on plaiting category, it can be divided into pure willow plaiting and mixed plaiting. The former is plaited products with willow twigs; the latter is plaited products with more than two kinds of materials, including willow, wood, rattan, bamboo, rope (paper, straw, hemp), plastic, metal and so on. To be more specific, it can also be divided into willow and wood, willow and rattan, willow and iron, willow and palm, rattan, willow and wood, straw, wood and willow, pure willow, willow and bamboo and so on. There are various finished products, including shopping basket, flower basket, fruit basket, wine basket, picnic basket, food basket, furniture, craft works, gift basket, antique basket, laundry basket and so on.

Indoor decoration consists of flower hanging basket in circular type, flower arranging basket in hexagon, flower hanging basket in square, with various types and sizes, bright and colorful, to decorate living room, bedroom and hotel, elegant and warm, which is common in modern indoor design.

\section{Artistic Characteristics of Straw and Willow Plaiting}

Straw and willow plaiting, as a traditional craft, is an antique art. Products in Primitive Period, contained the spiritual demand of human in addition to practical application. Traditionally, it is a practical art, which is an important aspect of folk art theme and style. From the perspective of material, it selects natural material and creates new indoor items according to natural features of materials, with aesthetic characteristics. The plain and natural folk craft works are full with unique national colors. After long-term development, Chinese traditional craft has gradually formed basic art form and process technology, and develops incessantly in generations. Therefore, the national feature of straw and willow plaiting is a main characteristics different from other folk craft arts.

\section{References}

[1] Luan Xinxia. The Application of Straw and Willow Plaiting in Furniture Design [J]. Commercial 
Culture (Academic Edition), 2009, (11).

[2] Gao Liyan. Research on the Application of Straw and Willow Plaiting and Brand Development [J]. Modern Enterprise Education, 2009, (14).

[3] Jiang Huiqing, Zhang Bing'e. Prosperous Straw and Willow Plaiting [J]. Agricultural Knowledge, 2009, (04).

[4] Yi Zhen. Popular Straw and Willow Plaiting Works Abroad [J]. Inter Trade, 1983, (05).

[5] Fang Qizhen, Gong Long. Top Ten Craft Works [J]. Co-operative Economy\& Science, 2001, (10). 